\title{
CIDADE INFORMACIONAL E IDENTIDADE: o porto alegrense narrado no Foursquare
}

\author{
Luis Fernando Herbert Massoni* \\ Valdir Jose Morigi $i^{\text {*t }}$
}

RESUMO Reflete sobre a identidade do cidadão porto alegrense a partir das informações publicadas em ambientes virtuais. Articula teoricamente os conceitos de identidade, cidade informacional e mídias locativas, para pensar a cidade formada pelas Tecnologias de Informação e Comunicação. Aborda a identidade como fruto de um processo de identificação que ocorre nos grupos sociais, sendo a cidade um espaço de construção identitária. Defende que as informações produzidas e divulgadas sobre o cidadão evidenciam suas marcas identitárias. A metodologia está calcada na análise das informações publicadas pelos usuários na página de Porto Alegre do Foursquare, aplicativo de celular onde constam informações sobre as cidades. A partir de uma abordagem qualitativa, o estudo utiliza o método da narratologia, que permite identificar e caracterizar as personagens em narrativas. Conclui que o porto alegrense possui uma representação identitária múltipla no aplicativo e suas características influenciam na concepção que os sujeitos possuem sobre a própria cidade.

Palavras-chave: Identidade. Cidade Informacional. Foursquare. Porto alegrense.

\begin{abstract}
- Mestre em Comunicação e Informação pela Universidade Federal do Rio Grande do Sul, Brasil. Doutorando no Programa de Pós-Graduação em Comunicação e Informação da Universidade Federal do Rio Grande do Sul, Brasil. Bolsista CAPES.

E-mail: luisfernandomassoni@gmail.com.

* Doutor em Sociologia pela Universidade de São Paulo, Brasil. Professor titular da Universidade Federal do Rio Grande do Sul, Brasil. Docente permanente no Programa de Pós-Graduação em Comunicação e Informação da Universidade Federal do Rio Grande do Sul, Brasil. E-mail: valdir.morigi@gmail.com.
\end{abstract}

\section{INTRODUÇÃO}

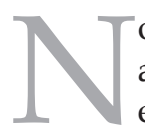

ossas identidades são formadas através de processos complexos que envolvem as diversas instituições e grupos sociais que nos rodeiam. Diferentemente de uma categoria estanque ou supostamente "herdada", a identidade é fruto de uma ação de identificação que ocorre nas esferas pública e privada, suscetível às transformações sociais. Além dos grupos em que nos inserimos, atuam nesse processo os lugares por onde transitamos, pois são elementos contextuais imprescindíveis em nossas práticas socioculturais. A cidade é o espaço público de convivência e divergência e nela afloram sociabilidades que influenciam nossas identidades.

A identidade, sendo um processo, nunca está livre de disputas, sendo constantemente moldada por discursos e interesses. Em um mundo cada vez mais globalizado, ela está em constante transformação, sendo também influenciada pelas informações que produzimos e acessamos sobre nós mesmos. Isso porque, em nossas práticas informacionais, narramos nossas vidas, assim como somos narrados pelo outro em suas práticas. A vida contemporânea do sujeito citadino está imersa em tecnologias que, através do compartilhamento de informações e interações em ambientes virtuais, influenciam as construções identitárias através das cidades informacionais por eles criadas.

Tendo isso em vista, propomos uma reflexão sobre a identidade dos sujeitos citadinos através das informações publicadas pelos cidadãos no Foursquare, aplicativo de celular que possibilita aos seus usuários compartilharem informações sobre os lugares das cidades as quais frequentam. $\mathrm{O}$ questionamento levantado nesse estudo é: Como é narrada a identidade do porto alegrense no aplicativo Foursquare? Para tanto, realizamos uma 
análise das informações divulgadas pelos usuários na página de Porto Alegre no aplicativo, orientando-nos pelo método da narratologia, que estrutura a análise das personagens a partir de suas características físicas, psicológicas, sociais, ideológicas e morais. Os resultados evidenciam que a identidade do porto alegrense é narrada de maneira múltipla no Foursquare e que suas características são fundamentais para a formação da concepção que os sujeitos possuem sobre a própria cidade.

\section{CIDADE INFORMACIONAL, MÍDIAS LOCATIVAS E IDENTIDADES}

Nosso contexto atual é marcado por fluxos globais de informação que rearticulam os modos de apropriação cultural e construção identitária. A produção, a circulação e o uso da informação nas redes sociais virtuais reconfiguram as concepções que possuímos sobre nós mesmos e sobre os outros. Tudo isso é fruto de complexos processos interativos calcados em práticas informacionais que têm no usuário um produtor de informações.

Esse contexto poderia ser fértil para a proliferação de teorias a respeito da suposta construção de uma identidade global, como se a globalização homogeneizasse a todos, igualando-nos. Entretanto, conforme Mattelart (2005, p. 97-98), não há identidade sem tradução, uma vez que "[...] cada sociedade retranscreve os signos transnacionais, adaptando-os, os reconstrói, reinterpreta-os, reterritorializa-os, 'ressemantiza-os'". Isso quer dizer que as trocas culturais realizadas nesse contexto são marcadas por processos de assimilação da informação recebida, que é apropriada a partir das concepções de mundo dos sujeitos locais. Ainda a esse respeito, Mattelart (2005) afirma que a dimensão global atua na reconfiguração das identidades, construindo novos imaginários por meio do trabalho mental das pessoas. Esses fluxos transformam nossa identidade, mas é fundamental concebermos esse processo como uma articulação entre o local e o global, na medida em que nossas marcas identitárias locais mantem-se ativas, sendo ressignificadas e não substituídas.

Para um indivíduo, sua identidade é a percepção do que ele é em relação ao mundo cultural e ao mundo natural e o sentimento de pertencimento ligado a essa percepção. É uma afirmação de seu lugar, de sua posição no mundo. É ainda a consciência que uma pessoa tem de si mesma. (COSTA, 2002, p. 145).

Conforme Hall (1999), nossas identidades são formadas culturalmente, o que significa que devemos pensa-las como construídas no interior da representação, através da cultura e não fora delas. Para o autor, a identidade é formada ao longo do tempo por meio de processos inconscientes, ou seja, não é algo que nasce conosco, pois a construímos através de nossas experiências e perspectivas. $\mathrm{O}$ autor ressalta que esse processo ocorre sob a influência de ideais imaginários ou fantasiosos. A identidade, nesse sentido, está sempre em construção, sendo inadequado falarmos em termos de uma identidade pronta, pois, para o autor, deveríamos falar em um processo de identificação. Assim, conforme Costa (2002), ao abordarmos a identidade, jamais estaremos nos referindo a uma substância ou atributo imutável dos indivíduos e das coletividades, pois ela está sendo constantemente reelaborada na interação entre os indivíduos.

Historicamente, à identidade foi atribuído o papel de unificar os indivíduos em torno de características em comum, de modo a fazêlos sentirem-se pertencentes a um coletivo ou a uma determinada cultura. Esse atributo altamente político da identidade lhe atribui um papel homogeneizador, na medida em que, para unificar uma dada comunidade em torno de características em comum, é necessário selecionar quais são essas características. Enquanto elemento que nos constitui, a identidade possui um caráter de permanência, na medida em que baliza nossas concepções de mundo, dando sentido às nossas práticas socioculturais.

Essa permanência está acompanhada da resistência e da continuidade, pois a identidade se apoia na memória para ser registrada e transmitida (COSTA, 2002). A construção dessas identidades é caracterizada pela busca de características e modos de vida típicos de uma nação, desenvolvendo-se através da escolha de determinadas características em detrimentos de outras. Como afirma Hall (1999, p. 59), "não importa quão diferentes seus membros possam ser em termos de classe, gênero ou raça, uma cultura nacional busca unificá-los numa identidade cultural, para representá-los todos 
como pertencendo à mesma e grande família nacional." Essa narrativa sobre a nação é uma estratégia política, na medida em que reforça a soberania nacional através da unificação do povo.

Entretanto, essa narrativa encontra obstáculos para manter sua estabilidade, especialmente devido à complexidade do multiculturalismo, das migrações e dos novos circuitos informacionais que caracterizam a comunicação do século XIX. Essa "grande família nacional" é permeada por tensões com outras famílias (os povos de outras nações, que lhe são externos) e entre seus próprios membros (as identidades regionais e urbanas, que lhe são internas).

Devido aos fluxos migratórios cada vez mais intensos (às vezes, até conflituosos), milhões de pessoas estão frequentemente em mudança, vivendo de forma mais ou menos duradoura em cidades diferentes das de sua origem, modificando seu estilo de vida ao mudar de contexto (GARCÍA CANCLINI, 2009). Nessa trama envolta por fluxos informacionais, as culturas urbanas pressionam a identidade nacional, ao se contraporem a ela através da construção de identidades locais próprias. Conforme García Canclini (2009), o bairro, a cidade e a nação são cenários de identificação. Entretanto, o autor salienta que também nos apropriamos de outros elementos disponíveis na sociedade através dos produtos consumidos, com a televisão e a própria experiência de viajar ou migrar de um país para outro. Isso significa que a cidade e a informação são elementos de identificação e de reforço ou questionamento de identidades.

A circulação pelos espaços da cidade, atrelada à questão da mobilidade urbana, é reforçada pela presença cada vez maior de Tecnologias de Informação e Comunicação (TICs) e, segundo Longhi (2009), atualmente isso ocorre por meio dos equipamentos de convergência midiática, que alteram nossa relação com o espaço que frequentamos. Para a autora, elas potencializam o processo de desterritorialização e desenraizamento social, criando territórios informacionais, conceito apontado por Lemos (2007b), que diz respeito às áreas de controle de fluxo informacional digital na intersecção entre o ciberespaço e o espaço urbano, sendo o controle e o acesso à informação realizados por meio de dispositivos móveis e redes sem fio. Segundo o autor, os territórios informacionais são o espaço movente e híbrido, que se forma na relação entre o espaço eletrônico e o físico.
Toda essa mobilidade urbana favorecida pelas tecnologias, atreladas a um fluxo informacional, potencializa a multiplicação das representações sobre a cidade e, por conseqüência, gera tensões na forma de interação entre os sujeitos e os objetos representados. Conforme Lemos (2003), as cidades contemporâneas estão sob o signo do digital, caracterizadas por um fluxo planetário de informações que circulam através de diversos dispositivos. Para o autor, vivemos nas cibercidades ${ }^{1}$, trazendo à tona novas questões a respeito da intersecção entre o lugar e o fluxo.

No contexto atual, as cidades se revelam como territórios de sistemas técnicos múltiplos, que são articulados por cruzamentos de forças globais que sofrem tensão devido às reconfigurações e criações locais (JOSGRILBERG, 2010). De acordo com Coelho (2010), é preciso estudar o impacto das tecnologias sobre a estruturação do território, concebendo o espaço geográfico como reflexo e condição de nossas práticas sociais. $\mathrm{O}$ autor cita que há uma interação entre o espaço herdado (a cidade industrial) e o espaço projetado (a cidade informacional), que é mediada pelo jogo de forças sociais que têm poder de reestruturar o território, promovendo a substituição e a articulação das funções da cidade, configurando a cidade digital como espaço projetado da cidade real.

É fundamental ponderarmos que essas novas interações virtuais com a cidade não anulam a cidade da forma como a concebemos, pois ela "persiste e resiste", como elucida Coelho (2010), produzindo novas utopias, mas pensada por meio de novos sujeitos coletivos responsáveis por interferir na produção do espaço através das redes locais e globais. Assim, a cidade se reorganiza a partir de uma materialidade técnica e informacional, articulando lugares e criando distintas identidades territoriais.

Em Souza e Jambeiro (2005) identificamos a "cidade informacional", conceito elaborado por Firmino $(2005)^{2}$, referindo-se à cidade do espaço de fluxos, transformada social,

\footnotetext{
I Na literatura consultada, identificamos termos como cibercidade, cidade digital, cidade virtual, cidade informacional e telecity para se referir ao mesmo fenômeno, que é a emergência de uma nova cidade a partir dos fluxos informacionais característicos das TICs.

2 FIRMINO, R. J. A simbiose do espaço: cidades virtuais, arquitetura recombinante e a atualização do espaço urbano. In: LEMOS, A. (Org.) Cibercidade II: a cidade na sociedade da informação. Rio de Janeiro: E-papers. 2005. p. 307-335.
} 
econômica e politicamente pelas TICs. Ela seria consequência da coexistência de espaços físicos (tradicionais) e virtuais (eletrônicos), considerando essas tecnologias como parte do processo de construção do espaço (FIRMINO, 2005 apud SOUZA; JAMBEIRO, 2005). De acordo com os autores, é necessário analisarmos a cidade a partir de seus aspectos materiais (redes físicas de estrutura urbana) e virtuais (espaços de fluxos construídos através de relações sociais).

A cidade informacional é a
representação urbana da sociedade
em rede, apresentando-se como um
ponto nodal de desenvolvimento social,
econômico e político, podendo ser
compreendida como um catalisador das
redes e dos fluxos urbanos, através das
convergências tecnológicas possibilitadas
pelas redes digitais de telecomunicações.
(SOUZA; JAMBEIRO, 2005, p. I0).

A transformação de nossas relações com a cidade por meio de dispositivos tecnológicos vem ocorrendo rapidamente e, ao mesmo tempo, de maneira quase natural, pois facilmente nos adaptamos às mais variadas tecnologias digitais e mídias delas decorrentes que chegam a nós a todo o momento. Conforme Cunha (2013), as redes sociais e plataformas tecnológicas que possibilitam a narração compartilhada podem proporcionar a inclusão narrativa, com base em tecnologias móveis.

As tecnologias sem fio transformam as relações entre pessoas e espaços urbanos, originando uma nova forma de mobilidade, que dá o tom à crise de fronteiras do sujeito, da identidade, do espaço geográfico, da cultura, da política, da economia, etc. (LEMOS, 2007a). Para o autor, a comunicação atual é "pós-massiva" e permite emitir, circular e se mover ao mesmo tempo, sendo seu diferencial a mobilidade informacional, que é feita por fluxos de informação, alterando a transição pelos espaços físicos da cidade. $\mathrm{O}$ autor cita as "mídias locativas", que são um conjunto de tecnologias digitais e processos info-comunicacionais com conteúdo informacional diretamente vinculado a um lugar específico, o que abrange a emissão e recepção de informações a partir de um determinado local, implicando uma relação entre lugares e dispositivos móveis digitais até então inédita (LEMOS, 2008).

Tais informações são processadas pelos artefatos sem fio cada vez mais presentes em nossas vidas, como os Sistemas de Posicionamento Global (GPS), telefones celulares, palms e laptops, redes Wi-Fi e Bluetooth, itens que agregam conteúdo digital à localidade e servem para monitorar, vigiar, mapear, geoprocessar, localizar, anotar ou jogar (LEMOS, 2008), dentre outras novas funções que a todo momento surgem. De acordo com Lemos (2008), através de uma relação estreita entre informação digital, localização e artefatos digitais móveis, os lugares dialogam com os dispositivos informacionais, enviando, coletando e processando dados.

$\mathrm{Na}$ concepção de Lemos (2008), as mídias locativas transformam o espaço urbano e a vivência nas grandes cidades, pois do fluxo massivo de informações passamos para uma forma de comunicação horizontal e multipolar. $\mathrm{O}$ autor afirma que a paisagem comunicacional contemporânea é formada pelos processos comunicacionais massivos, mas também pelos pós-massivos, que são customizados e qualquer um pode contribuir com informações, sendo que as mídias locativas vêm reforçando a hibridação do espaço físico com o ciberespaço.

As mídias locativas permitem a troca de informação em mobilidade, o que fornece dados dinâmicos e resignifica um determinado ambiente (LEMOS, 2008). O que está em jogo aqui é a possibilidade de o cidadão expressar seu ponto de vista sobre a cidade em tempo real, registrando suas impressões e opiniões sobre a urbe em um ambiente virtual. Tais opiniões se tornam informações virtuais que enriquecem o escopo de conteúdos sobre a cidade disponíveis a outros cidadãos, muitas vezes de forma instantânea.

Como percebemos, esse é um processo não apenas marcado pelo acelerado desenvolvimento de novas tecnologias, mas também por uma mutação na forma de lidar com elas. Calcadas em uma conectividade jamais vista antes e expressiva velocidade de fluxos informacionais, as mídias locativas vão além do papel historicamente desenvolvido pela mídia na relação com a cidade, pois essas novas práticas de mobilidade comunicacional criam novas relações sociais e apropriações do espaço urbano (LEMOS, 2008). Todos esses avanços permitiram uma relação maior entre o ciberespaço e o espaço urbano e, consequentemente, transformações na nossa relação com ambos.

É inegável que o vínculo que estabelecemos com a cidade, incluindo nossa forma e olhá- 
la, caminhar por ela e percebê-la, é diferente quando portamos um dispositivo móvel. As características desses novos recursos técnicos, conforme Cunha (2013), nos desorientam, intimidam, perturbam, confundem, distorcem e alucinam, pois "[...] as escalas, potenciais e velocidades envolvidos nos novos equipamentos e instalações excedem as proporções e as limitadas possibilidades de percepção, força e deslocamento do corpo humano." De qualquer modo, Cunha (2013) compreende que é nesse cenário que os sujeitos tornam-se narradores da cidade, tecendo uma grande rede que forma uma cidade virtual, influenciada pela dimensão coletiva, mas ancorada em fragmentos de percepções individuais.

Explorar a cidade portando um dispositivo móvel ou mesmo explorá-la à distância, acessando informações sobre ela através dele, nos possibilita novas experiências com o ambiente urbano, sendo que tal processo não está livre dos ruídos e potencialidades que caracterizam qualquer forma de comunicação. Todo esse contexto, marcado por mudanças técnicas incessantes, nos permite uma relação maior entre o ciberespaço e o espaço urbano e, consequentemente, transformações na nossa relação com ambos. As mídias locativas nos permitem um olhar especial sobre a cidade informacional que aqui vislumbramos, reconfigurando a forma como nos apropriamos do ambiente urbano. Se a cidade e a informação são elementos fundamentais em nossa construção identitária, então estamos diante também de um novo contexto de produção da identificação com a urbe.

\section{ASPECTOS CONTEXTUAIS METODOLÓGICOS}

Este estudo está calcado em uma abordagem qualitativa, pois o que nos interessa é explorar a subjetividade dos indivíduos, percebendo a forma como o cidadão porto alegrense é narrado no aplicativo Foursquare. Nosso objetivo é estudar a identidade dos cidadãos por meio das informações divulgadas no aplicativo, algo que nos permita desvendar as representações, os enquadramentos e os estereótipos que guiam os comportamentos frente à vida e às práticas socioculturais no ambiente urbano.
Sendo a cidade uma construção imaginária dos cidadãos, sendo que são eles que lhe dão efervescência cultural, nos propomos a estudar a sua identidade a partir da perspectiva deles, ou seja, do que eles "têm a dizer" a seu respeito. Desse modo, escolhemos como método de pesquisa a narratologia, calcando-nos na análise das narrativas que os cidadãos produzem sobre o porto alegrense e compartilham na página da cidade no Foursquare. A seguir apresentamos o aplicativo Foursquare e esplanamos acerca do método da narratologia, destacando suas constribuições para nossa pesquisa.

\section{I Foursquare: informação, cidade e identidade na palma da mão}

O Foursquare é um aplicativo de geolocalização no qual as informações nele compartilhadas são contribuições dos usuários, meio em que se manifesta a subjetividade que pretendemos explorar. Trata-se de uma rede social virtual gratuita que, utilizando localização inteligente, proporciona experiências com o ambiente urbano. Pertence à empresa de mesmo nome, com sede em Nova Iorque e, de acordo com Pellanda (2011), foi concebido em 2008 por Dennis Crowley e Naveen Selvadurai, embora a versão final pública seja de 2009. De acordo com o autor, o Foursquare é um expoente da convergência tecnológica entre as novas tecnologias e os softwares dos sistemas operacionais dos aparatos móveis, permitindo a ligação do contexto geográfico com informações no ciberespaço, configurando-se como um pioneiro modo de contextualização do espaço físico.

Ao utilizar o Foursquare, os indivíduos têm acesso a recomendações de lugares próximos ou localizados em um terminado local. É possível pesquisar no aplicativo e encontrar informações sobre restaurantes, bares, shoppings, museus, monumentos, cidades, ruas, bairros, dentre outros. O aplicativo também permite que o usuário avalie o lugar e é apresentada a nota média dada a ele, que varia entre 0 e 10 e é baseada nas avaliações de todos os usuários. O usuário avalia o quanto "curte" o lugar, em que é possível marcar três opções, conforme exposto na Figura 1. 
Figura 1: Opções de Avaliações dos Lugares no Aplicativo Foursquare

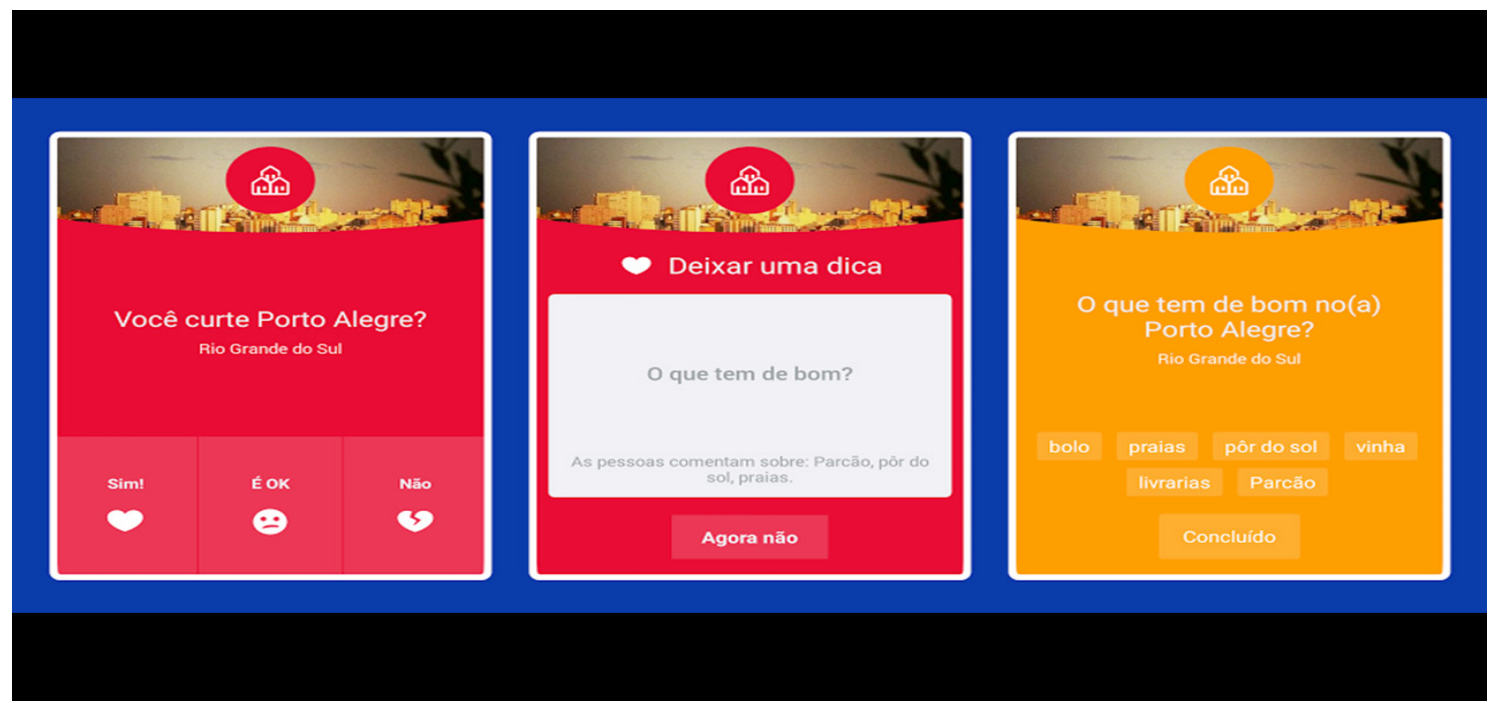

Fonte: adaptado do aplicativo Foursquare

Logo após, é possível deixar uma "dica" sobre o lugar, enfatizando o que ele "tem de bom". Nesse momento, além de escrever um texto, é possível postar uma foto relacionada ao local. A pessoa também pode "Salvar", o que permite recuperar posteriormente com maior facilidade o local pesquisado, assim como quando a pessoa clica para "Curtir" um lugar. A opção "O que você precisa saber" apresenta as "dicas" dadas por outras pessoas àquele local. Desse modo, o aplicativo orienta o usuário por meio de um fluxo de informações, que se forma de acordo com o seu trânsito pela cidade. Por outro lado, vale lembrar que o usuário também pode obter "dicas" sobre lugares sem nem mesmo sair de casa, através do sistema de busca do aplicativo, com a possibilidade, inclusive, de pesquisar lugares por meio de um mapa.

Conforme Sousa e Cunha (2012), o aplicativo permite a anexação de um sentido aos lugares, fazendo com que o espaço perca seu caráter abstrato e genérico, pois estamos nos referindo à constituição do lugar. Para os autores, emana a partir das narrativas dos sujeitos sobre a localidade um senso de subjetividade, identidade e história edificado através das relações das pessoas com aquele ponto do espaço. As geografias pessoais e coletivas constituídas pela dinâmica lúdica do serviço não são simplesmente homogêneas e nem negações do formato tradicional do lugar, uma vez que as localizações marcadas e comentadas possuem significado para os usuários. O foco dos usuários, para Sousa e Cunha (2012), não é a mera explanação do espaço urbano, mas sim o estabelecimento de vínculos com seus pares, dos quais derivam os sentidos.

De acordo com Cunha (2011), o Foursquare é uma rede na qual a narrativa está conectada diretamente ao lugar, configurando-se como um repositório de informações virtuais sobre a cidade, auxiliando através das narrativas dos cidadãos a construção das memórias da cidade. Nas palavras da autora, "[...] a soma das narrativas pode ser transformada em um único texto que dá conta da história dos lugares, pela percepção e narração oficial e também através da narração dos sujeitos pelas redes." (CUNHA, 2013, p. 123). O Foursquare possibilita analisarmos narrativas dos cidadãos sobre Porto Alegre, desvendando as representações que circulam sobre o ambiente urbano e seus transeuntes, que são elementos centrais na construção subjetiva da cidade e dos cidadãos.

\subsection{Narratologia}

Uma das potencialidades dos ambientes virtuais é o acesso às percepções dos mais variados sujeitos e grupos sociais, que têm nas 
redes sociais virtuais a possibilidade de produzir e publicar opiniões, que nada mais são do que informações. Ao nos expressarmos nessas redes, disseminamos informações através de narrativas que revelam nossas visões de mundo. Isso significa que o produtor da informação torna-se um narrador, responsável por dar o enquadramento que lhe convém à história narrada. As redes sociais são espaços narrativos da experiência vivida e, de acordo com Motta (2013), a contemporaneidade nos desafia a observar a comunicação narrativa através dos novos meios tecnológicos que viabilizam criativas e inovadoras formas narrativas.

Para Motta (2013), narrar é relatar eventos de nosso interesse em um suceder temporal encaminhado para um desfecho, relatando processos de mudança, alteração e sucessão interrelacionados. Segundo o autor, nossas narrativas tecem nossas vidas, nos entrelaçam, envolvem, representam e constituem, criando as representações de nós mesmos e nossas identidades individuais. Já para Barbosa (2003, p. 87), a identidade “[...] é marcada por uma interação entre ficção e experiência que encontra na narrativa o campo privilegiado desse exercício." A narrativa nunca é a verdade, mas sim uma versão dos fatos, uma percepção contada e influenciada pelos ideais e valores de quem a narra. Para Barbosa (2003), a narrativa fornece versões parciais da realidade devido à tensão na sua relação com a experiência. Desse modo, no momento em que estudamos narrativas, identificamos também resquícios de memórias individuais dos sujeitos narradores, além das suas identidades.

De acordo com Barbosa (2003), a identidade depende ontologicamente da narração, pois as narrativas elaboram a identidade pessoal do sujeito que conta a história de sua vida. Segundo o autor, a narrativa transforma os eventos em episódios e os atores sociais em personagens, proporcionando um enriquecimento substancial da identidade, que se forma na dinâmica entre a experiência e a narrativa.

Tendo em vista que este estudo investiga as informações sobre o porto alegrense publicadas no Foursquare e que, para tanto, as concebemos como narrativas, lançamos mão do método da narratologia, que propõe a análise de narrativas através da observação de sua estrutura. O objetivo da narratologia é, para Motta (2013, p. 79), “[...] entender como os sujeitos sociais constroem intersubjetivamente seus significados pela apreensão, representação e expressão narrativa da realidade." $\mathrm{O}$ autor entende a narratologia como a teoria da narrativa e os métodos e procedimentos que empregamos na análise de narrativas humanas, configurandose como um método de análise das práticas culturais.

Ao analisarmos narrativas, é necessário ter em mente que elas contam uma história, sendo compostas por uma série de elementos que dão o sentido desejado pelo narrador. Conforme Gancho (2002), a narrativa é estruturada sobre cinco elementos fundamentais: enredo: conjunto dos fatos de uma história, também chamado intriga, ação, tema, etc.; personagens: ser responsável pelo desempenho do enredo, ou seja, quem faz a ação. Possuem características físicas, psicológicas, sociais, ideológicas e morais; tempo: inclui a época em que se passa a história, sua duração, o tempo cronológico e o tempo psicológico; espaço: lugar onde se passa a ação, tendo as funções principais e situar as ações dos personagens e estabelecer uma interação com eles; narrador: é o elemento estruturador da história, estando ele em primeira ou terceira pessoa.

Entendendo que as "dicas" deixadas pelos usuários do Foursquare formam uma narrativa sobre a cidade, propomos uma análise delas, enfocando os aspectos relacionados acerca das personagens - características físicas, psicológicas, sociais, ideológicas e morais. Salientamos que, devido ao caráter inexato ou incompleto de algumas "dicas" deixadas pelos usuários, em alguns momentos não foi possível identificar todas essas caracteríticas a respeito do porto alegrense, mas buscamos traçar algumas características sobre sua identidade a partir dessas informações.

O procedimento de coleta de dados delimitou o corpus utilizado neste estudo. À luz da narratologia - especialmente dos aspectos sobre observação dos personagens -, analisamos a página da cidade de Porto Alegre no Foursquare, objetivando identificar como se configura a identidade do porto alegrense nas narrativas ali divulgadas. Cabe salientarmos que coletamos as "dicas" compartilhadas pelos cidadãos desde o início do funcionamento do aplicativo, em 2009, até março de 2016. O motivo da escolha 
desse recorte temporal é o aniversário da cidade, comemorado em 26 de março. Devido a questões éticas, resguardamos a identidade dos sujeitos que publicaram as "dicas" analisadas neste estudo.

\section{A IDENTIDADE DO PORTO ALEGRENSE NO APLICATIVO FOURSQUARE}

Apresentamos aqui os resultados da pesquisa, com a discussão dos dados referentes às dicas publicadas pelos usuários na página da cidade de Porto Alegre no Foursquare. De acordo com o aplicativo, 222.468 era o total de frequentadores da cidade (frequência dos usuários do aplicativo, a partir das curtidas e checkins realizados). Identificamos 212 dicas publicadas pelos usuários, respeitandose o recorte temporal previsto (início do funcionamento do aplicativo até 26 de março de 2016, data do aniversário da cidade). Conforme o Gráfico 1, percebemos que os cidadãos compartilham no aplicativo majoritariamente elogios à cidade, seus espaços, rotina, cultura e demais elementos que a caracterizam, o que corresponde a $62 \%$ dos conteúdos publicados.

Gráfico 1: Conteúdos das Dicas Compartilhadas sobre Porto Alegre no Foursquare

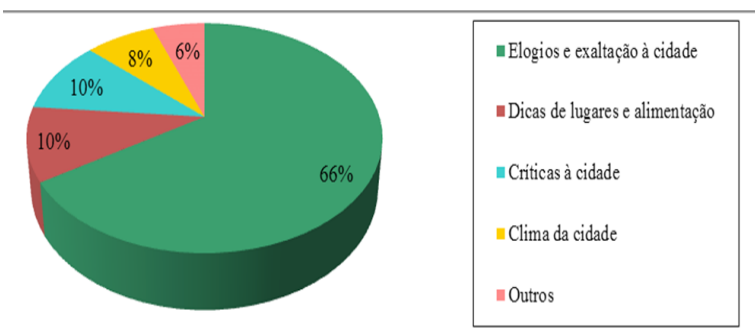

Fonte: dados da pesquisa, 2017

Grande parte dos usuários demonstram admiração e carinho por Porto Alegre, através de apelidos como "Portinho" ou "Porto dos Casais" ${ }^{\prime 3}$. A cidade é tida como cosmopolita, aberta à diversidade de modos de vida, o que fica evidente em "dicas" que a descrevem como uma "cidade de várias culturas". De acordo com

3 Porto Dos Casais foi um dos nomes dados à cidade em alusão à chegada, em 1752, dos primeiros casais vindos das ilhas dos Açores.
Costa (2002), a identidade é uma consciência que a pessoa possui sobre si mesma, mas esse "eu" é múltiplo, pois não se trata de uma simples entidade homogênea, mas um conjunto de identidades variadas. Como afirma autora, "[...] as cidades contemporâneas com suas múltiplas identidades possuem uma cultura diversificada que, no entanto, é capaz de dar alma ao tecido urbano se tratada com carinho e com respeito." (COSTA, 2002, p. 151). A partir disso, os cidadãos concebem a cidade como um lugar de múltiplas identidades, na medida em que não há apenas um tipo de sujeito que a frequente - ela seria, assim, um espaço de diversidade identitária.

Prevalecem concepções positivas sobre Porto Alegre, que é citada como um "lugar de gente feliz". Alguns usuários narraram os porto alegrenses como "gente boa", calorosos, receptivos e educados, "sem muito esforço para serem agradáveis". No processo de representação da cidade, a ela são conferidas as características de seus moradores: nas palavras dos cidadãos, Porto Alegre é uma "cidade sorriso". Essa atribuição de características humanas à cidade decorre do fato de que o ambiente urbano é uma construção social, não existe por si só, pois são seus transeuntes que lhe dão a dinâmica cotidiana. Nesse sentido, o "sorriso" ao qual o usuário se refere não é da cidade, mas de seus cidadãos, representados aqui como pessoas felizes.

As informações publicadas no Foursquare revelam tanto as visões do próprio porto alegrense, expressas em trechos como "o melhor lugar do mundo é a casa da gente", como também a visão dos outros - um usuário a cita como um dos três melhores lugares que já visitou. Sendo assim, identificamos que não são apenas porto alegrenses que publicam informações no aplicativo, na medida em que turistas também o fazem. Para García Canclini (2009), perante as atuais condições de comunicação globalizada, é preciso considerar a complexidade das formas de interação, recusa, apreço, discriminação ou hostilidade em relação aos outros, pois esse é um contexto de confrontação assídua. Em narrativas como as do Foursquare, constatamos essa confrontação, uma vez que a identidade do porto alegrense reproduzida nesse ambiente não é construída apenas pela sua própria percepção de si, mas também dos outros. 
Obviamente, essas concepções positivas sobre o cidadão compõem uma narrativa sobre a cidade, muitas vezes amparada em outros discursos, como do turismo e das mídias massivas locais como o jornal, o rádio e a televisão. Como elucida Costa (2002), é fabricada uma cultura para atrair o turista, muitas vezes forçando a criação de uma identidade manipulada por grupos específicos. Esse aspecto pode ser identificado nas narrativas construídas pelos cidadãos no Foursquare, na medida em que, por mais que se coloquem como produtores das informações, eles sempre são influenciados por narrativas externas, com tendências à reprodução delas.

A identidade gaúcha também está presente nas narrativas sobre a cidade, tanto que, quando os usuários citam alimentos típicos de Porto Alegre, lembram do "churrasco" e do "chimarrão", iguarias da culinária gaúcha, reconhecidos como símbolos das tradições e da cultura gaúcha. Ao indicarem atividades a se fazer na "capital dos gaúchos", como é citada, alguns usuários sugerem dançar vanera ${ }^{4}$ em um Centro de Tradições Gaúchas (CTG) e experienciar a língua gaúcha (falar "bah" e "tchê"), em uma clara alusão aos gentílicos do povo gaúcho. Observamos que a identidade do porto alegrense é fortemente influenciada pelas marcas em que está assentada a identidade cultural regional, pois seus elementos estão presentes nas atividades que dinamizam a cidade, na sua culinária e até nos sotaques da população.

Essa percepção sobre o citadino de Porto Alegre está relacionada à vinculação de sua identidade à tradição gaúcha, fortalecendo sua ligação com os mitos de origem do homem do campo. De acordo com Oliven (2006), a identidade é construída a partir de delimitações geográficas, sejam nacionais ou regionais, buscando na tradição a justificativa de sua existência - mesmo que essa tradição seja, às vezes, (re)apropriada ou mesmo inventada. Possamai (2013) utiliza o termo "kit identidade" para se referir ao conjunto de elementos que são apresentados como constituintes de nossa identidade, tais como a bandeira, o hino, a língua, o calendário cívico, as datas comemorativas,

4 Estilo de dança de origem alemã típica do Rio Grande do Sul, de Santa Catarina e do Paraná. entre outros. Para os gaúchos, esse "kit" seria configurado por objetos e costumes "típicos" - ou que, pelo menos, boa parte considere que sejam.

Nesse sentido, reduzir a identidade porto alegrense à identidade gaúcha é uma prática questionável, pois, embora inserido na cultura gaúcha, as suas práticas cotidianas pouco traduzem tal "herança", na medida em que muitos elementos que compõem esse "kit" não são observados em seu dia a dia. A vida urbana exige certas adequações: a paisagem pastoril é trocada pelo arranha céus, os cavalos dão lugar aos automóveis, a bombacha aos ternos ou roupas mais casuais, a vanera disputa espaço com o pop e outros ritmos musicais mais apreciados pelos cidadãos, em um cotidiano no qual a identidade gaúcha "pura" não encontra espaço fecundo. Essa forma de ver o cidadão e sua relação com o espaço, a partir de categorias dicotômicas "cidade" e o "campo", o "urbano" e o "rural" para definir a identidade dos sujeitos parece não ser tão fértil em tempos de globalização em que os fluxos informacionais afetam a vida social.

Apesar de prevalecer uma visão "apaixonada" sobre a cidade, também identificamos críticas. Por outro lado, também há afirmações de que os porto alegrenses são "grossos demais", ríspidos e ignorantes. Um dos usuários critica justamente o orgulho presente nas narrativas dos outros cidadãos: "Uma pena que todo esse bairrismo e amor pela cidade deixe tantos moradores cegos e não consigam enxergar o caos que esta cidade vive hoje." Aqui identificamos mais uma representação: a ideia de que o cidadão porto alegrense é "bairrista", ou seja, acredita que a sua cidade é sempre melhor do que outros lugares - consequentemente, considera que seu povo é mais virtuoso do que os demais. Além disso, o emprego do termo "hoje" por parte desse cidadão revela que esse "bairrismo" do porto alegrense decorre do seu apego ao passado, tido como mais virtuoso do que o presente.

\section{CONSIDERAÇÕES FINAIS}

Moldada pelo contato com a cidade e pelo acesso à informação, a identidade é um aspecto fundamental de nossa existência enquanto sujeitos sociais. As identidades culturais são processos em permanente construção, não 
estando jamais prontas, mas reformuladas em nossas experiências com os outros, com a cidade e com a informação. As identidades precisam ser pensadas não mais a partir da sua fixidez, mas enquanto processos híbridos e móveis, estando contemporaneamente suscetíveis à transformação através das TICs que cada vez mais fazem parte de nosso cotidiano.

A construção da identidade cultural dos porto alegrenses pensada a partir dos compartilhamentos das informações no Foursquare evidencia algumas características desse grupo. Fica evidente nessas narrativas a ideia de serem "receptivos" e "educados". O sotaque, os gentílicos e as outras marcas do falar porto alegrense também ajudam na construção dessas personagens, ressaltando-se o prazer de estar em sua companhia. Entretanto, essa mesma figura "carismática" e "afetuosa" é tida por alguns usuários como "bairrista", reforçando uma concepção já conhecida do gaúcho. Além disso, a ideia de serem grosseiros e ignorantes pode remeter à figura do gaúcho do campo, tido nesse caso como arredio e ríspido.

Enquanto método de pesquisa, a narratologia auxiliou o desenvolvimento desta pesquisa ao indicar categorias de análise a serem pensadas na observação do objeto estudado. Constituindo uma narrativa, o conjunto de "dicas" analisado tem como elemento central as características do porto alegrense, aqui concebido como personagem que dá sentido a esta trama. Além disso, a reflexão sobre o método em si evidencia a forte relação entre as narrativas e a identidade, o que legitima este método como adequado para o emprego deste tipo de estudo.

Artigo recebido em 26/0I/20I8 e aceito para publicação em 22/02/20 I8

\title{
INFORMATIONAL CITY AND IDENTITY: the porto alegrense narrated in the Foursquare
}

\begin{abstract}
It reflects on the identity of the citizen port alegrense from the information published in virtual environments. Theoretically articulates the concepts of identity, informational city and locative media, to think about the city formed by Information and Communication Technologies. It addresses identity as the result of a process of identification that occurs in social groups, the city being a space of identity construction. Defends that the information produced and disclosed about the citizen evidences his identity marks. The methodology is based on the analysis of the information published by the users in the Porto Alegre page of Foursquare, a mobile app where information about the cities are shown. From a qualitative approach, the study uses the method of narratology, which allows to identify and characterize the characters in narratives. It concludes that the porto alegrense has a multiple identity representation in the app and its characteristics influence the conception that the subjects have about the city itself.
\end{abstract}

Keywords: $\quad$ Identity. Informational City. Foursquare. Porto alegrense.

\section{REFERÊNCIAS}

BARBOSA, M. F. Experiência e narrativa. Salvador: Edufba, 2003.

COELHO, F. D. A cidade digital e a apropriação social da inovação tecnológica. In: SILVEIRA, S. A. (Org.). Cidadania e redes digitais. São Paulo: Comitê Gestor da Internet no Brasil, 2010. p. 183205.
COSTA, H. H. F G. Culturas urbanas: identidades e diversidades. In: POSSAMAI, Z. R.; ORTIZ, V. (Org.). Cidade e memória na globalização. Porto Alegre: Unidade Editorial da Secretaria Municipal de Cultura, 2002. p. 141157.

CUNHA, M. R. A memória na era da reconexão e do esquecimento. Em Questão, Porto Alegre, v. 17, n. 2, p. 101-115, jul./dez. 2011. 
CUNHA, M. R. Cidade e memória nas redes sociais na internet. ECO-Pós, Rio de Janeiro, v. 16, n. 3, p. 113-128, set./dez. 2013.

GANCHO, C. V. Como analisar narrativas. São Paulo: Ática, 2002.

GARCÍA CANCLINI, N. A cultura extraviada nas suas definições. In: Diferentes, desiguais e desconectados: mapas da interculturalidade. 3. ed. Rio de Janeiro: Editora UFRJ, 2009. p. 35-53.

HALL, S. A identidade cultural na pósmodernidade. 3. ed. Rio de Janeiro: DP\&A, 1999.

JOSGRILBERG, F. B. A opção radical pela comunicação na cidade. In: SILVEIRA, S. A. (Org.). Cidadania e redes digitais. São Paulo: Comitê Gestor da Internet no Brasil, 2010. p. 153181.

LEMOS, A. Cibercultura: alguns pontos para compreender a nossa época. In: LEMOS, A.; CUNHA, P. (Org.). Olhares sobre a cibercultura. Porto Alegre: Sulina, 2003. p. 11-23.

LEMOS, A. Cidade e mobilidade. Telefones celulares, funções pós-massivas e territórios informacionais. Matrizes, São Paulo, v. 1, n. 1, p. 121-137, out. 2007a.

LEMOS, A. Comunicação e práticas sociais no espaço urbano: as características dos Dispositivos Híbridos Móveis de Conexão Multirredes (DHMCM). Comunicação, Mídia e Consumo, São Paulo, v. 4, n. 10, p. 23-40, 2007 b.

LEMOS, A. Mídia locativa e territórios informacionais. In: SANTAELLA, L.; ARANTES, P. (Org.). Estéticas tecnológicas: novos modos de sentir. São Paulo: Educ, 2008.

LONGHI, C. R. Facetas da esfera pública contemporânea através das representações midiáticas do espaço urbano. In: HELLER, B.; LONGHI, C. R. (Org.). Representações em trânsito: personagens e lugares na cultura midiática. São Paulo: Porto de Ideias, 2009. p. 1634.

MATTELART, A. A circularidade global/ local. In: Diversidade cultural e mundialização. São Paulo: Parábola, 2005. p. 89111.

MOTTA, L. G. Análise crítica da narrativa. Brasília: Editora UnB, 2013.

MOTTA, L. G. Análise crítica da narrativa. Brasília: Editora UnB, 2013.

OLIVEN, R. G. A parte e o todo: a diversidade cultural no Brasil-nação. 2. ed. Petrópolis: Vozes, 2006.

PELLANDA, E. C. A conexão entre lugares e espaços proporcionada pela rede Foursquare. Intexto, Porto Alegre, v. 1, n. 24, p. 164-175, jan./ jun. 2011.

POSSAMAI, Z. R. Patrimônio e identidade: qual o lugar da História? In: GASPAROTTO, A.; FRAGA, H. J.; BERGAMASCHI, M. A. (Org.). Ensino de História no Cone Sul: patrimônio cultural, territórios e fronteiras. Porto Alegre: Evangraf/UNIPAMPA, 2013. p. 87-98.

SOUZA, L.; JAMBEIRO, O. Cidades informacionais: as cidades na era da informação. ENCONTRO NACIONAL DE CIÊNCIA DA INFORMAÇÃO, 6., 2005. Salvador. Anais... 2005.

SOUZA; P. V.; CUNHA, R. E. S. Entre o ser e o estar: a representação do eu e do lugar no Foursquare. In: RIBEIRO, J. C.; FALCÃO, T.; SILVA, T. (Org.). Mídias sociais: saberes e representações. Salvador: EDUFBA, 2012. p. 3147. 